\title{
Left hemisphere language lateralization in bilinguals and monolinguals
}

\author{
CARLOS SOARES and FRANÇOIS GROSJEAN \\ Northeastern University, Boston, Massachusetts 02115
}

\begin{abstract}
Tachistoscopic studies of lateralization in bilinguals suggest that there is a greater degree of right hemisphere involvement in their processing of language than is typically found in monolinguals. However, most of the studies reviewed failed to control the sex, handedness, and degree of fluency of the subjects and did not include a monolingual comparison group. The present study used adult right-handed males (Portuguese-English bilinguals and Englishspeaking monolinguals) in a tachistoscopic word-reading task. In Experiment 1, the words from the bilinguals' two languages were presented in mixed blocks, while in Experiment 2, they were presented in separate blocks. The results were: (1) a similar level of left hemisphere advantage for language in the bilingual and the monolingual groups, (2) no evidence of greater heterogeneity of asymmetry patterns in bilinguals, and (3) a significant correlation $(r=.61)$ for lateralization levels of the bilinguals' two languages. These results indicate that language is processed primarily in the left hemisphere of both bilinguals and monolinguals.
\end{abstract}

Converging evidence indicates that the left cerebral hemisphere (LH) is specialized or dominant for language functions, while the right hemisphere (RH) is superior for the processing of visuospatial information. This evidence has been obtained from a wide variety of sources, including studies of unilateral brain damage (Geschwind, 1970, 1972, 1979; Milner, 1974), neuroanatomy (Galaburda, LeMay, Kemper, \& Geschwind, 1978; Galaburda, Sanides, \& Geschwind, 1978; Geschwind \& Levitski, 1968), stimulation of the cortex (Ojemann \& Mateer, 1979; Penfield \& Roberts, 1959), chemical anesthetization of the brain (Wada \& Rasmussen, 1960), split-brain patients (Gazzaniga, 1970; Levy, Trevarthen, \& Sperry, 1972; Zaidel, 1978), and differential hemispheric presentation of stimuli to normal subjects (Bradshaw \& Gates, 1978; Kimura, 1973; Kimura \& Durnford, 1974; Pirozzolo, 1977; Studdert-Kennedy \& Shankweiler, 1970; White, 1969, 1972, 1973). However, this is not to say that one hemisphere can mediate a certain function, while the other cannot. Instead, it can be said that certain stimulus-response relations can be processed faster or more accurately

This study is part of the first author's doctoral thesis under the supervision of the second author. This research was supported by HEW Biomedical Research Support Grant RR 07143 to the two authors and NIH Grant NS 14923 to the second author. We would especially like to thank Steve Harkins, Harlan Lane, Joanne Miller, Loraine Obler, Michael Terman, Jyotsna Vaid, and Robert Zatorre for their comments on earlier drafts of this paper. Portions of this research were presented at the American Psychological Association convention, Montreal, Canada, 1980. Address correspondence to: Carlos Soares, Psychology Department, 234 NI, 360 Huntington Avenue, Boston, Massachusetts 02115. by one hemisphere than by the other in the performance of a certain task. For example, the RH, although specialized for the processing of visuospatial information, can also perform a variety of linguistic functions, although not as efficiently or to the same degree as the LH (Curtiss, 1977; Searleman, 1977; Zaidel, 1978).

Recently, there has been an increase in research attempting to determine how this pattern of hemispheric specialization might be affected by the knowledge and use of a second language (for reviews, see Galloway, 1981b; Vaid \& Genesee, 1980). A number of studies have examined language processing in neurologically intact bilinguals, using a traditional technique for assessing hemispheric dominancetachistoscopic presentation of words. The results have been mixed: Some studies show the typical LH advantage, while in others there is an indication of a greater degree of RH involvement in language processing than is usually found in monolinguals. This finding of greater heterogeneity of hemispheric dominance patterns in normal bilinguals has received independent support from reviews of case studies of bilingual aphasics. Albert and Obler (1978) and Galloway (1981a) found a higher incidence of aphasia in bilinguals due to lesions in the RH than is typical of monolingual samples. Therefore, it would appear that the acquisition of a second language leads to new patterns of hemispheric functioning. If this were the case, theories of the neuropsychology of language would have to account for the emergence of the RH as an equal or even dominant language processor when a second language is learned and used. However, many of the existing case studies of bilingual 
aphasics are incomplete with respect to the linguistic capabilities of the patients and to other factors, such as handedness, which could affect the lateralization of hemispheric functions. Moreover, there may well be a bias in the literature toward presenting deviant instances of aphasia in bilinguals (Vaid \& Genesee, 1980).

A review of the tachistoscopic studies with normal bilinguals also reveals a failure to control a number of variables that by themselves affect language lateralization and, therefore, leave unresolved any possible effects due to bilingualism. The first of these variables is the sex of the subjects: Language functions may be more bilaterally represented in females than in males (Bradshaw \& Gates, 1978; Bradshaw, Gates, \& Nettleton, 1977; Hannay \& Malone, 1976; Lake \& Bryden, 1976; McGlone, 1980; McKeever \& Van Deventer, 1977; Piazza, 1980). The second variable is the handedness of the subjects: Left-handers are more likely to show greater proportions of $\mathrm{RH}$ language involvement (Briggs \& Nebes, 1976; Bryden, 1965; Goodglass \& Quadfasel, 1954; Hécaen \& Sauget, 1971; Lake \& Bryden, 1976; McKeever, Van Deventer, \& Suberi, 1973). Furthermore, in hemispheric dominance studies with bilinguals, their proficiency in the two languages must be assessed, and monolingual controls must be included in order to provide a direct comparison of monolingual and bilingual performance with identical procedures, apparatus, and stimuli.

For example, the early tachistoscopic studies by Mishkin and Forgays (1952) and by Orbach (1952) found LH superiority for English words in EnglishHebrew bilinguals but no differential lateralization of Yiddish or Hebrew words. On the other hand, when right-handed bilingual males were used, $\mathrm{LH}$ dominance for both Hebrew and English was obtained by Barton, Goodglass, and Shai (1965) and by Orbach (1967). Kershner and Jeng (1972) found similar results with Chinese-English bilinguals. However, bilingual proficiency was not assessed in any of these studies, and only Barton et al. (1965) used monolingual (English) controls. A recent study by Walters and Zatorre (1978) selected proficient, righthanded Spanish-English bilinguals and found overall LH superiority. However, analysis of the data from individual subjects revealed that a higher percentage exhibited RH advantage or no differential lateralization in one or both languages than is usually found in monolingual samples. Hamers and Lambert (1977) obtained a similar pattern of results (i.e., overall LH advantage, but greater individual heterogeneity in lateralization) in a language identification task with right-handed French-English bilinguals screened for language proficiency. However, neither of these studies controlled for sex of subject or included a monolingual control group.

The present study, therefore, examines the effect of bilingualism on hemispheric language dominance, using normal subjects and tachistoscopic presentation of words, while controlling the sex, handedness, and language proficiency of the bilinguals, and including monolingual controls. In addition, this study uses balanced bilinguals who came into contact with their second language after the age of 12 . These choices permit the examination of two proposals that have been made with regard to the possible sources of RH dominance in bilinguals (Galloway, $1981 \mathrm{~b}$ ). First, balanced bilinguals (those who are equally fluent in both languages) show lower overall degrees of language asymmetry. Second, balanced bilinguals may develop different hemispheric processing strategies depending on the age of initial exposure to their second language. In particular, it has been proposed that late bilinguals (whose bilingual experience started after the age of 12) use a right-hemisphere-based "gestalt-like or melodic" strategy to classify words as belonging to one language or the other (Genesee, Hamers, Lambert, Mononen, Seitz, \& Starck, 1978).

\section{EXPERIMENT 1}

\section{Method}

Subjects. Ten male Portuguese-English bilinguals (ages 21-35; mean $=25.7$ ), whose first language was Portuguese and who came first into contact with English after the age of 12, and 10 male English-speaking monolinguals (ages 20-39; mean $=25.7$ ) participated in this study. All subjects were strong right-handers, as determined by a short questionnaire developed from Bryden (1977) and Oldfield (1971), with no left-handers in the immediate family. The bilinguals were selected for approximately equal and high degree of fluency in Portuguese and English. Their language proficiency was assessed by a questionnaire in which the subjects rated their fluency in reading, writing, speaking, and understanding of Portuguese and English; a reading test in which subjects were timed in reading aloud Portuguese and English passages of equal length; and a naming task in which subjects named objects found in various settings in $1 \mathrm{~min}$. Subjects had to rate their overall fluency in English and Portuguese as equal, read the passages in approximately the same time $( \pm 10 \%)$, and name approximately the same number of objects $( \pm 15 \%)$. In addition, care was taken to ensure that bilinguals used both languages regularly. All of the bilinguals moved to the United States in their adolescence and, therefore, learned English in school and through interactions with their English-speaking friends and the community in general.

Stimuli. The stimuli were $\mathbf{4 0}$ English nouns of medium to high frequency (mean $=100.45$; range, 10 to 371 ), according to the analysis by Kučera and Francis (1967), and their 40 Portuguese translations. The words (two to six letters in length) were printed horizontally in black letters on $5 \times 7$ in. white cards using rub-on letters (C-THRU Graphics, Helvetica Medium, $30 \mathrm{pt}$ ) and centered $2 \mathrm{deg} 23 \mathrm{~min}$ to the right or to the left of the fixation point.

Procedure. Each word was presented unilaterally, once to the right and once to the left visual field, through a tachistoscopic (Scientific Prototype, Model GB-320) for a duration of $150 \mathrm{msec}$. Order of presentation to right and left visual fields was random.

For the bilingual group, the Portuguese and the English words were randomly mixed. The monolinguals were exposed only to the English words. Subjects in the monolingual group received a series of 18 practice trials with equal presentations to the right and left visual fields, whereas the bilinguals had 36 practice trials with an equal number of Portuguese and English words and equal presentations to the right and left visual fields. In each 
trial, the experimenter said "Ready" when the stimulus card had been inserted in the tachistoscope. The subject then fixated on an $X$ located at the center of the field, pressed a key that activated the tachistoscope, and read the word aloud as fast as possible. Reaction times were measured by a PDP-11 computer as the time from the onset of word presentation to the onset of vocalization as measured by a voice-operated relay. Bradshaw and Gates (1978) and White (1973) have shown that this procedure is effective in producing differential hemispheric performance.

\section{Results and Discussion}

Figure 1 shows the mean reaction times (for correct responses only) for the English words presented to monolinguals and bilinguals (left side of the figure) and for the Portuguese words presented to the bilinguals (right side of figure) as a function of visual field. It is clear that words were named faster when presented to the right visual field (RVF), indicating left hemisphere dominance for both groups. This is true also for the two languages in the bilinguals. In addition, the monolingual group responded faster overall than the bilingual group.

These observations were confirmed by two analyses of variance. First, bilingual and monolingual performance was examined for the English words [ 2 groups (monolingual and bilingual) by 2 visual fields (right and left), with subjects and words as random variables (Clark, 1973)]. Both main effects were significant. In overall reaction time, the monolinguals (874 $\mathrm{msec})$ were significantly faster than the bilinguals $(1,200 \mathrm{msec})\left[\mathrm{F}^{\prime}(1,18)=22.22, \mathrm{p}<.001\right]$, and responses were faster to words presented in RVF (997 msec) than in LVF $(1,078 \mathrm{msec})\left[\mathrm{F}^{\prime}(1,20)=6.58\right.$, $\mathrm{p}<.001]$, thus indicating left hemisphere superiority in this task. The Group by Field interaction was not significant $\left[F^{\prime}(1,21)=.51, p>.40\right]$, show-

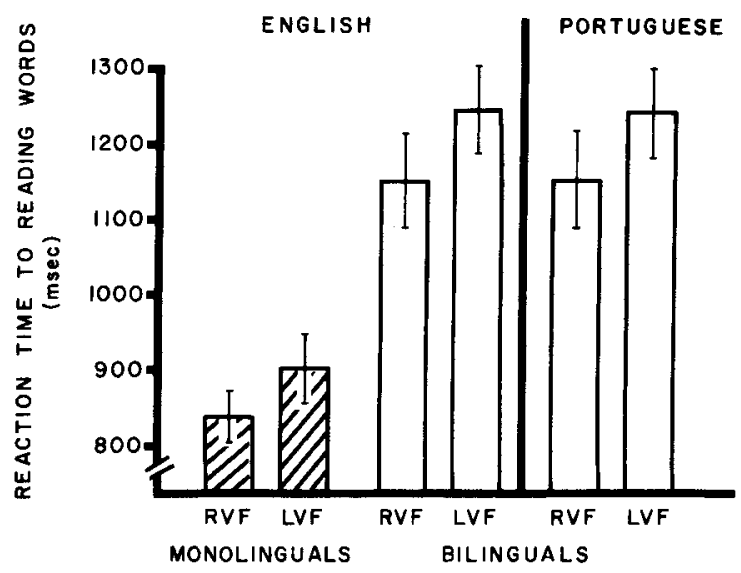

Figure 1. Reaction times for reading English words presented to monolinguals and for Portuguese and English words presented to bilinguals as a function of visual field (RVF = right visual field; LVF = left visual field) in Experiment 1. For bilinguals, Portuguese and English words were presented in randomly mixed order. Faster reaction times for reading words presented to RVF indicate left hemisphere superiority. Bars indicate 1 SE on either side of the mean. ing that although the bilinguals responded slower than did the monolinguals, the level of left hemisphere dominance for language processing in both groups is similar. Indeed, this is illustrated by the identical ratios of mean reaction times for right and left visual fields: monolinguals $=.93$; bilinguals (English) $=.92$.

The second analysis of variance examined the responses of the bilinguals to the Portuguese and English words [ 2 languages (English and Portuguese) by 2 visual fields (right and left), with subjects and words as random variables]. Only the main effect of visual field was significant. As in the previous analysis, words were read significantly faster when presented to RVF (RVF $=1,155 ; \mathrm{LVF}=1,243)\left[\mathrm{F}^{\prime}(1,9)\right.$ $=5.20, \mathrm{p}<.05]$. Again, the left hemisphere was superior to the right in mediating this task. The main effect of language was not significant [English = $1,200 \mathrm{msec}$; Portuguese $=1,198 \mathrm{msec} ; \mathrm{F}^{\prime}(1,13)=$ $.006, p>.90$ ], indicating that the bilinguals were equally proficient in the two languages. The Language by Field interaction was not significant $\left[F^{\prime}(1,10)=\right.$ $.08, p>.70$ ], suggesting a similar level of lateralization for the two languages. The ratios of mean reaction times for right and left visual fields show this: English $=.92$; Portuguese $=.93$.

Individual data were then analyzed in order to determine whether the bilinguals might exhibit a greater heterogeneity in patterns of hemispheric asymmetry, even though the group data showed overall LH advantage. The results show, to the contrary, that a high degree of similarity exists in patterns of hemispheric dominance for bilinguals and monolinguals. In the monolingual group, eight subjects exhibited LH superiority, while two exhibited RH advantage or no differential lateralization; in the bilingual group, the corresponding numbers are eight and two for the English words and seven and three for the Portuguese words.

It can be concluded, therefore, that when relevant variables are controlled, similar patterns of left hemisphere dominance for language processing are found in monolinguals and bilinguals. Furthermore, since our bilingual subjects were balanced and had come into contact with their second language after 12 years of age, these two variables cannot be posited as possible sources of increased right hemisphere involvement in the language processing of bilinguals. However, the fact that the bilinguals respond significantly more slowly than do the monolinguals was a point of concern. Bilinguals may indeed be slower than monolinguals at performing language-related tasks. Or, more likely, the difference was due to the procedure of mixing words randomly from the two languages and visual field presentations so that, on any trial, the subject did not know the language of the word or the visual field in which it would appear. In contrast, only the visual field was randomized for the monolingual subjects. The bilingual 
subjects, therefore, had to perform a more difficult task and, clearly, more time was required to complete it. Furthermore, this increased task difficulty could have produced or at least enhanced the level of left hemisphere dominance in the bilinguals, as lateralization research in the auditory modality has shown (Godfrey, 1974). In order to resolve this potential confounding variable, a second experiment was conducted in which a different group of bilinguals was presented the English and Portuguese words in separate blocks.

\section{EXPERIMENT 2}

\section{Method}

Subjects. Ten male Portuguese-English bilinguals (ages 20-30; mean $=22.7$ ), who did not take part in Experiment 1 but fulfilled all of the screening criteria, served as subjects.

Stimuli. The stimuli were the same as in Experiment 1.

Procedure. The procedure was the same as in Experiment 1 except that the two languages were presented in separate blocks. For all subjects, the English words were presented first, followed by the Portuguese words. Before each language block, the subjects received 18 practice trials in which words for the appropriate language were presented an equal number of times to each visual field.

\section{Results and Discussion}

The mean reaction times (for correct responses only) for the English and Portuguese words presented to the bilingual subjects in Experiment 2 as a function of visual field are shown in Figure 2, along with those for the English words for the monolingual controls of Experiment 1. First, it is apparent that when the two languages are presented separately, bilinguals respond as rapidly as monolinguals. Second, the RVF (LH) superiority is maintained, suggesting that the LH dominance obtained in the bilinguals

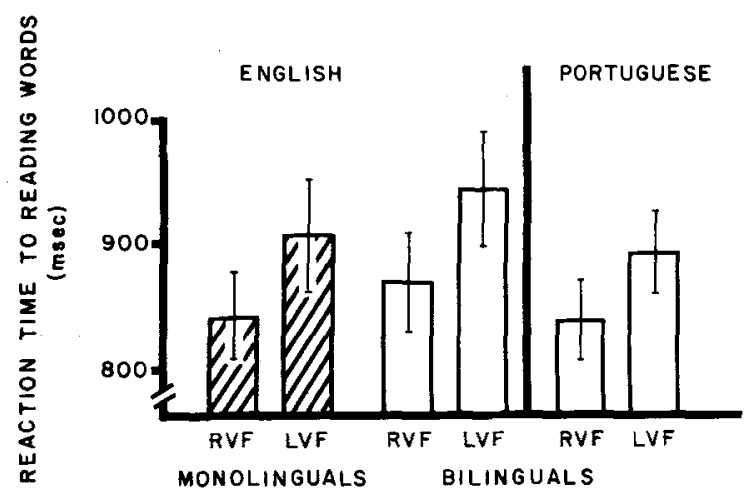

Figure 2. Reaction times for reading English words presented to monolinguals (from Experiment 1) and for Portuguese and English words presented to bilinguals as a function of visual field (RVF = right visual field; LVF = left visual field) in Experiment 2. For bilinguals, Portuguese and English words were presented in separate blocks. Faster reaction times for reading words presented to RVF indicate left hemisphere superiority. Bars indicate 1 SE on either side of the mean. in Experiment 1 was not due to the difficulty of their task. Furthermore, Portuguese and English seem to be lateralized to the same degree.

The results of two analyses of variance confirmed these observations. First, the performances of the monolingual controls in Experiment 1 and the bilinguals in Experiment 2 on the English words were analyzed [ 2 groups (monolingual and bilingual) by 2 visual fields (right and left), with subjects and words as random variables]. Only the main effect of visual field was significant. Once again, responses to words presented in RVF ( $856 \mathrm{msec}$ ) were faster than those in LVF $(925 \mathrm{msec})\left[F^{\prime}(1,20)=16.08\right.$, $\mathrm{p}<.0011$, indicating LH superiority. Overall reaction times for the two groups were not significantly different [monolinguals $=874 \mathrm{msec}$, bilinguals = $907 \mathrm{msec} ; \mathrm{F}^{\prime}(1,21)=.32, \mathrm{p}>.50$ ], demonstrating that, at the word level, comparable performances can be obtained in monolinguals and bilinguals when the two languages of the bilingual are presented separately. The Group by Visual Field interaction also was not significant $\left[F^{\prime}(1,17)=.03, p>.80\right]$, indicating that, for both groups, language processing is lateralized to the same extent. Once again, the ratios of mean reaction times for right and left visual fields are identical: monolinguals (from Experiment 1) $=.93$; bilinguals (English) $=.92$.

The second analysis of variance examined the responses of the bilinguals to the Portuguese and the English words [2 languages (Portuguese and English) by 2 visual fields (right and left), with subjects and words as random variables]. The only significant effect was visual field. Words were read faster when presented to RVF (854 msec) than to LVF $(916 \mathrm{msec})$ $\left[F^{\prime}(1,12)=11.92, p<.005\right]$, again demonstrating LH advantage. As with the first group of bilinguals, the main effect of language was not significant [English $=907 \mathrm{msec}$, Portuguese $=863 \mathrm{msec} ; \mathrm{F}^{\prime}(1,15)$ $=4.10, p>.05]$, indicating that the bilinguals were equally proficient in both languages. In addition, the Language by Visual Field interaction was not significant $\left[F^{\prime}(1,10)=1.11, p>.30\right]$, again suggesting similar levels of lateralization for the two languages. The ratios of mean reaction times for right and left visual fields clearly show this: English $=.92$, Portuguese $=.94$.

Individual data were analyzed as in Experiment 1. Again, identical numbers of subjects in the monolingual and bilingual groups exhibited LH superiority. For the monolinguals (from Experiment 1), as well as for the bilinguals (two languages), eight subjects exhibited LH advantage, while two showed RH superiority or no differential lateralization. (This was the case for both languages.) These results, together with those obtained in Experiment 1, provide no support. for the findings of greater heterogeneity in patterns of asymmetry reported by Hamers and Lambert (1977) and by Walters and Zatorre (1978). However, neither of those studies controlled for the sex of the subjects. 
The results of Experiment 2, therefore, confirm those obtained in Experiment 1 by showing that task difficulty per se did not produce or enhance the level of LH dominance in the language processing of bilinguals.

Another point of interest was the degree of correspondence between the lateralization values of the bilinguals' two languages. A Pearson product-moment correlation coefficient was computed for the right-left visual field ratios for all 20 bilinguals. The result was $r=.61$, which agrees well with the values reported by Walters and Zatorre (1978; $r=.63$ ) and by Piazza and Zatorre $(1981 ; r=.58)$. Therefore, the extent of asymmetry in one of the bilingual's languages is indeed related to that of the other.

\section{GENERAL DISCUSSION}

The results of these two experiments indicate that when relevant variables are controlled, LH dominance in language processing is similar in bilinguals and monolinguals. Furthermore, since our subjects were balanced late bilinguals, the age of onset of second language experience and the degree of fluency in the two languages can no longer be posited as possible sources of greater levels of RH involvement in language processing.

Recent studies of language lateralization in the auditory modality, using the dichotic listening paradigm, support and extend our conclusions. Galloway (1981a) tested male right-handed Spanish speakers who were just beginning to acquire English informally and found LH superiority for both languages at levels similar to those obtained in English and Spanish monolingual controls. Gordon (1980) examined male and female right-handed Hebrew-English bilinguals. The results showed that the same pattern of LH dominance was obtained for both languages, regardless of when the second language was learned, how long it had been used, or how well it was known. Furthermore, females yielded smaller lateralization scores than males. Thus, our findings that $\mathrm{LH}$ dominance is present in balanced late bilinguals can now be extended to those just beginning to acquire a second language informally, to those who are more or less fluent in a second language, and to those who use their second language only irregularly. In addition, Piazza and Zatorre (1981) have shown that bilingual (Spanish-English) children, aged 9:6 and 13:6, exhibit similar levels of LH superiority in both languages, demonstrating that the pattern of language lateralization appears stable in development. Although there are additional variables that might show an increase in RH involvement in the language processing of bilinguals (e.g., manner of acquisition, cognitive strategies, "cultural" bias, etc.), it seems likely that our main effect will show generality, with language processed by $\mathrm{LH}$ to the same extent in monolinguals and bilinguals.

\section{REFERENCES}

Albert, M. L., \& Obler, L. K. The bilingual brain. New York: Academic Press, 1978.

Barton, M., Goodglass, H., \& Shai, A. Differential recognition of tachistoscopically-presented English and Hebrew words in the right and left visual fields. Perceptual and Motor Skills, $1965,21,431-437$.

Bradshaw, J. L., \& Gates, A. Visual field differences in verbal tasks: Effects of task familiarity and sex of subject. Brain and Language, 1978, 5, 166-187.

Bradshaw, J. L., Gates, A., \& NetTleton, N. C. Bihemispheric involvement in lexical decisions: Handedness and a possible sex difference. Neuropsychologia, 1977, 15, 277-286.

Brigas, G. G., \& Nebes, R. D. The effects of handedness, family history, and sex on the performance of a dichotic listening task. Neuropsychologia, 1976, 14, 129-134.

Bryden, M. P. Tachistoscopic recognition, handedness, and cerebral dominance. Neuropsychologia, 1965, 3, 1-8.

BRyden, M. P. Measuring handedness with questionnaires. Neuropsychologia, 1977, 15, 617-624.

Clark, H. C. The language-as-fixed-effect fallacy: A critique of language statistics in psychological research. Journal of Verbal Learning and Verbal Behavior, 1973, 12, 335-359.

Curtiss, S. Genie: A psycholinguistic study of a modern-day "wild-child." New York: Academic Press, 1977.

Galaburda, A. M., LeMay, M., Kempen, T. L., \& Geschwind, N. Right-left asymmetries in the brain. Science, 1978, 199, 852-856.

Galaburda, A. M., Sanides, F., \& Geschwind, N. Cytoarchitectonic left-right asymmetries in the temporal speech region. Archives of Neurology, 1978, 35, 812-817.

GaLLOWAy, L. M. Cerebral organization of language in bilinguals and second language learners. Doctoral dissertation, Department of Linguistics, University of California, Los Angeles, 1981. (a)

Galloway, L. M. Towards a neuropsychological model of bilingualism and second language performance: $\mathbf{A}$ theoretical article with a critical review of current research and some new hypotheses. In M. Long, S. Peck, X. Bailey (Eds.), Research in second language acquisition. Rowley, Mass: Newbury House, 1981 , in press. (b)

Gazzaniga, M. S. The bisected brain. New York: AppletonCentury-Crofts, 1970.

Genesee, F., Hamers, J., Lambert, W. E., Mononen, L., Seitz, M., \& StarcK, R. Language processing in bilinguals. Brain and Language, 1978, 5, 1-12.

Geschwind, N. The organization of language and the brain. Science, 1970, 170, 940-944.

Geschwind, N. Language and the brain. Scientific American, 1972, 226, 76-83.

Geschwind, N. Specializations of the human brain. Scientific American, 1979, 241, 180-199.

Geschwind, N., \& Levitsky, W. Human brain: Left-right asymmetries in temporal speech region. Science, 1968, 161, 186-187.

Godrrey, J. J. Perceptual difficulty and the right ear advantage for vowels. Brain and Language, 1974, 1, 323-335.

Goodolass, H., \& Quadrasel, F. A. Language laterality in left-handed aphasics. Brain, 1954, $77,521-548$.

GoRdoN, H. W. Cerebral organization in bilinguals. I. Lateralization. Brain and Language, 1980, 9, 255-268.

Hamers, J. F., \& Lambert, W. E. Visual field and cerebral hemisphere preference in bilinguals. In S. J. Segalowitz \& F. A. Gruber (Eds.), Lanģuage development and neurological theory. New York: Academic Press, 1977.

HannaY, H. J., \& Malone, D. R. Visual field effects and shortterm memory for verbal material. Neuropsychologia, 1976, 14, 203-209.

Hécaen, H., \& Sauget, J. Cerebral dominance in left-handed subjects. Cortex, 1971, 7, 19-48.

Kershnen, J. R., \& Jeng, A. G. R. Dual functioning hemi- 
spheric asymmetry in visual perception: Effects of ocular dominance and post exposural processes. Neuropsychologia, 1972, $10,437-445$.

KimurA, D. The asymmetry of the human brain. Scientific American, 1973, 228, 70-78.

Kimura, D., \& Durnford, M. Normal studies on the function of right hemisphere vision. In S. J. Dimond \& J. G. Beaumont (Eds.), Hemisphere function in the human brain. London: Elek, 1974.

Kučera, F., \& Francis, W. Computational analysis of present day American English. Providence, R.I: Brown University Press, 1967.

LAKE, D., \& Bryden, M. P. Handedness and sex differences in hemispheric asymmetry. Brain and Language, 1976, 3, 266-282.

Levy, J., Trevarthen, C., \& Sperry, R. W. Perception of bilateral chimeric pictures following hemispheric deconnection. Brain, 1972, 95, 61-78.

McGlone, J. Sex differences in human brain asymmetry: A critical survey. Behavioral and Brain Sciences, 1980, 3, 215-263.

McKeeven, W. F., \& Van Deventer, A. D. Visual and auditory language processing asymmetries: Influences of handedness, familial sinistrality, and sex. Cortex, 1977, 13, 225-241.

McKeever, W. F., Van Deventen, A. D., \& Suberi, M. Avowed, assessed and familial handedness and differential hemispheric processing of brief sequential and non-sequential visual stimuli. Neuropsychologia, 1973, 11, 235-238.

Milnen, B. Hemispheric specialization: Scopes and limits. In F. O. Schmitt \& F. G. Worden (Eds.), The neurosciences: Third study program. Cambridge, Mass: M.I.T. Press, 1974.

Mishixin, M., \& Forgays, D. G. Word recognition as a function of retinal locus. Journal of Experimental Psychology, 1952, 43, $43-48$.

Ojemann, G., \& Mateer, C. Human language cortex: Localization of memory, syntax, and sequential motor-phoneme identification systems. Science, 1979, 205, 1401-1403.

OLDFIELD, R. C. The assessment and analysis of handedness: The Edinburgh Inventory. Neuropsychologia, 1971, 9, 97-113.

Orbach, J. Retinal locus as a factor in the recognition of visually perceived words. American Journal of Psychology, 1952, 65, 555-562.

Orsach, J. Differential recognition of Hebrew and English words in right and left visual fields as a function of cerebral dominance and reading habits. Neuropsychologia, 1967, 5, 127-134.

Penfield, W., \& Roberts, L. Speech and brain-mechanisms. New York: Atheneum, 1959.

Piazza, D. The influence of sex and handedness in the hemispheric specialization of verbal and nonverbal tasks. Neuropsychologia, 1980, 18, 163-176.

Pinzza, D. M., \& Zatorre, R. J. A right ear advantage for dichotic listening in bilingual children. Brain and Language, 1981 , in press.

Pinozzolo, F. J. Lateral asymmetries in visual perception: A review of tachistoscopic visual half-field studies. Perceptual and Motor Skills, 1977, 45, 695-701.

Searleman, A. A review of right hemisphere linguistic capabilities. Psychological Bulletin, 1977, 84, 503-528.

Studdert-Kennedy, M., \& Shankweiler, D. Hemispheric specialization for speech perception. Journal of the Acoustical Society of America, 1970, 48, 579-594.

VAID, J., \& GENESEe, F. Neuropsychological approaches to bilingualism: A critical review. Canadian Journal of Psychology, $1980,34,419-447$.

WADA, J., \& RAsmUSSEN, T. Intracarotid injection of sodium amytal for lateralization of cerebral dominance. Journal of Neurosurgery, 1960, 17, 266-282.

WALters, J., \& ZATORRE, R. J. Laterality differences for word identification in bilinguals. Brain and Language, 1978, 6, 158.167.

White, M. Laterality differences in perception: A review. Psychological Bulletin, 1969, 72, 387-405.

WHITE, M. Hemispheric asymmetries in tachistoscopic information processing. British Journal of Psychology, 1972, 62, 497-508.

WhITE, M. J. Vocal and manual response latencies to bilateral and unilateral tachistoscopic letter displays. Quarterly Journal of Experimental Psychology, 1973, 25, 41-47.

Zaidel, E. Lexical organization in the right hemisphere. In P. A. Buser \& A. Rougel-Buser (Eds.), Cerebral correlates of conscious experience. Amsterdam: Elsevier, 1978.

(Received for publication January 19, 1981; accepted March 19, 1981.) 